\title{
Development of a spectro-electrochemical cell for soft X-ray photon-in photon-out spectroscopy
}

Tomoko Ishihara, Takashi Tokushima, Yuka Horikawa, Masaru Kato, and Ichizo Yagi

Citation: Review of Scientific Instruments 88, 104101 (2017);

View online: https://doi.org/10.1063/1.4997820

View Table of Contents: http://aip.scitation.org/toc/rsi/88/10

Published by the American Institute of Physics

\section{Articles you may be interested in}

X-ray spectrometer having 12000 resolving power at $8 \mathrm{keV}$ energy

Review of Scientific Instruments 88, 103107 (2017); 10.1063/1.4999995

A multi-purpose reaction cell for the investigation of reactions under solvothermal conditions Review of Scientific Instruments 88, 104102 (2017); 10.1063/1.4999688

An optical fiber Bragg grating and piezoelectric ceramic voltage sensor Review of Scientific Instruments 88, 105005 (2017); 10.1063/1.4986046

X-ray microtomography system for small and light samples using a flat panel detector Review of Scientific Instruments 88, 105112 (2017); 10.1063/1.4996368

A general approach to obtain soft x-ray transparency for thin films grown on bulk substrates Review of Scientific Instruments 88, 103701 (2017); 10.1063/1.5006522

Hardware for dynamic quantum computing

Review of Scientific Instruments 88, 104703 (2017); 10.1063/1.5006525

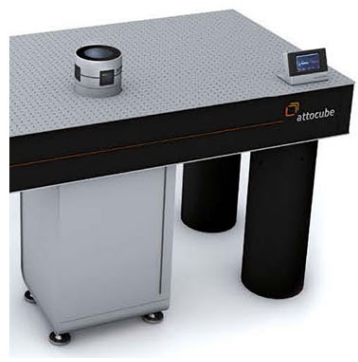

Obstruction free access

optical table with integrated cryocooler

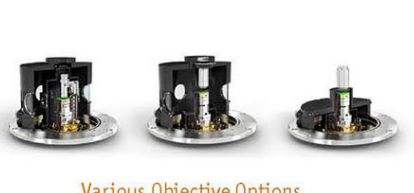

Various Objective Options

\section{attoDRY800}

- Cryogenic Temperatures

- Ultra-Low Vibration

- Optical Table Included

- Fast Cooldown
$5 \%$ DISCOUNT

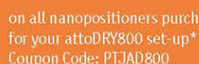

attocube 


\title{
Development of a spectro-electrochemical cell for soft X-ray photon-in photon-out spectroscopy
}

\author{
Tomoko Ishihara, ${ }^{1}$ Takashi Tokushima, ${ }^{1}$ Yuka Horikawa, ${ }^{1,2}$ Masaru Kato, ${ }^{3}$ and Ichizo Yagi ${ }^{3}$ \\ ${ }^{1}$ Soft X-ray Spectroscopy Instrumentation Unit, RIKEN SPring-8 Center, 1-1-1 Kouto, Sayo-cho, Sayo-gun, \\ Hyogo 679-5148, Japan \\ ${ }^{2}$ Department of Physics and Information Science, Faculty of Science, Yamaguchi University, 1677-1 Yoshida, \\ Yamaguchi 753-8512, Japan \\ ${ }^{3}$ Faculty of Environmental Earth Science, Hokkaido University, N10W5, Kita-ku, Sapporo, \\ Hokkaido 060-0810, Japan
}

(Received 27 July 2017; accepted 1 October 2017; published online 20 October 2017)

\begin{abstract}
We developed a spectro-electrochemical cell for X-ray absorption and X-ray emission spectroscopy, which are element-specific methods to study local electronic structures in the soft X-ray region. In the usual electrochemical measurement setup, the electrode is placed in solution, and the surface/interface region of the electrode is not normally accessible by soft X-rays that have low penetration depth in liquids. To realize soft X-ray observation of electrochemical reactions, a 15-nm-thick Pt layer was deposited on a 150-nm-thick film window with an adhesive 3-nm-thick Ti layer for use as both the working electrode and the separator window between vacuum and a sample liquid under atmospheric pressure. The designed three-electrode electrochemical cell consists of a Pt film on a SiC window, a platinized Pt wire, and a commercial $\mathrm{Ag} \mid \mathrm{AgCl}$ electrode as the working, counter, and reference electrodes, respectively. The functionality of the cell was tested by cyclic voltammetry and X-ray absorption and emission spectroscopy. As a demonstration, the electroplating of $\mathrm{Pb}$ on the $\mathrm{Pt} / \mathrm{SiC}$ membrane window was measured by X-ray absorption and real-time monitoring of fluorescence intensity at the $\mathrm{O} 1 \mathrm{~s}$ excitation. Published by AIP Publishing. https://doi.org/10.1063/1.4997820
\end{abstract}

\section{INTRODUCTION}

Electrochemical reactions are driven by electric potentials and normally occur at solid-liquid interfaces. Electrochemical reactions are utilized in electric batteries including rechargeable batteries to store and generate electricity. Fuel cells also utilize these reactions to generate electricity. Sometimes, electrochemical reactions are used for synthesizing new materials such as gold nanorods, ${ }^{1}$ conductive polymer nanotubes, ${ }^{2}$ and graphene oxide ${ }^{3}$ as well as for coating, such as the well-known electroplating. These reactions have been mainly investigated by electrochemical methods such as cyclic voltammetry (CV). Although $\mathrm{CV}$ is a sensitive method for electrochemical surface reactions, it only measures electric currents. To obtain more information, electrochemical quartz crystal microbalance (EQCM), Raman spectroscopy, ultraviolet-visible absorption spectroscopy, and infrared absorption spectroscopy are widely used in combination with $\mathrm{CV}$.

Furthermore, knowledge of the reaction mechanism is essential for understanding the electrochemical reactions. The electronic states of the reactant and products are especially important for a full understanding of the reaction. However, the above-mentioned methods may not provide such information. Recently, X-ray absorption spectroscopy (XAS) and X-ray emission spectroscopy (XES), which are elementspecific methods for studying local electronic structures, have been applied to liquid as well as gas and solid samples. Especially, the soft X-ray region below $1 \mathrm{keV}$ contains core levels of chemically important light elements such as $\mathrm{C}, \mathrm{N}$, and $\mathrm{O}$. Hence, electronic states of liquids and solutions have been extensively studied by means of soft X-rays using these new experimental techniques. . $^{4-6}$

Although spectro-electrochemical cells for the visible and infrared regions are commercially available, only a few designs have been reported for the soft X-ray region below $1 \mathrm{keV}$. For example, a liquid flow cell using a thin-film membrane as the window was developed to study the electrochemical corrosion of a copper surface in a sodium bicarbonate solution by means of Fe 2 p XAS. ${ }^{7}$ In this cell design, a thin copper film was thermally deposited on the window surface for use as a working electrode. The same research group reported the stability of a sample on the window for $\mathrm{CV}$ and $\mathrm{O} 1 \mathrm{~s}$ XAS measurements. ${ }^{8}$ A transmission-type liquid cell with built-in electrodes was also developed, and the redox behavior of iron cations in an aqueous electrolyte containing iron sulfate was studied by Fe L-edge XAS measurements. ${ }^{9}$

We have previously developed a liquid flow cell, which has a thin film window to separate vacuum and the liquid samples, for soft X-ray photon-in photon-out experiments and used it to study liquid systems including aqueous solutions. ${ }^{5,6}$ Based on this liquid flow cell design, in this study we developed a spectro-electrochemical cell for soft X-ray measurements. The design of the cell and its performance in soft X-ray emission and absorption experiments are reported.

\section{DESIGN OF SPECTRO-ELECTROCHEMICAL CELL FOR SOFT X-RAY EXPERIMENTS}

During voltammetry using three-electrode cells, electrochemical reactions occurring at the surfaces of the working electrodes are monitored by electrochemical analyzers, which 
allow one to control the electrochemical potential of the working electrode and acquire the current. In this configuration, it is difficult to observe the electrode surfaces by soft X-rays. The reason is that the electrodes, normally kept in solutions, are not accessible by soft X-rays which have low penetration depth in liquids (typically below $1 \mu \mathrm{m}$ ). However, if we adopt a film electrode thin enough to transmit soft X-rays, the photon-in photon-out experiments, e.g., fluorescence yield X-ray absorption spectroscopy (FY-XAS) and XES, could be carried out at the electrode/electrolyte interface with soft X-ray. In the current study, the three-electrode spectro-electrochemical cell for soft X-rays (Fig. 1) was designed based on our previously developed liquid flow-through cells. ${ }^{10}$ Based on the design of standard electrochemical cells, a $\mathrm{Ag} / \mathrm{AgCl}$ electrode (3M KCl, Thermo Scientific 66EE009) was chosen as the reference electrode. A Pt wire covered with electroplated $\mathrm{Pt}$ black was used as the counter electrode. The working electrode consisted of a deposited thin 15-nm-thick Pt metal layer on a film window. We chose a commercially available 150-nm-thick SiC membrane that comes with a 15-nm-thick Pt deposition layer and a 3-nm-thick Ti adhesive layer on the surface (NTT-AT, Japan). These surface layers face the liquid side. Electrochemical reactions on the surface of the working electrode were observed through this thin film window in the backside illumination configuration. To define the area of the working electrode and to secure the window, a perfluoro-elastomer sheet was used, which had an opening of $1 \mathrm{~mm} \times 4 \mathrm{~mm}$ that is slightly larger than the membrane film

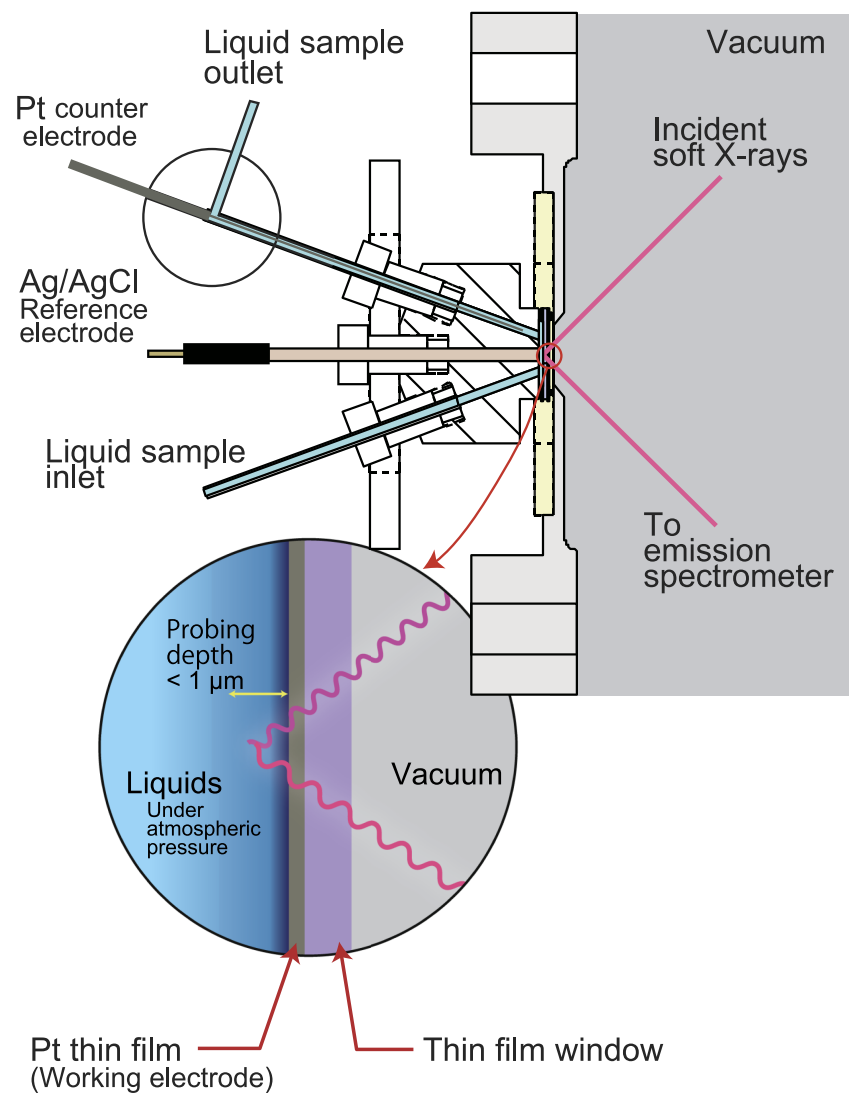

FIG. 1. Schematic view of the developed spectro-electrochemical cell for $\mathrm{X}$-ray spectroscopy in the soft X-ray region. Structure of a working electrode, a thin film SiC window with a Pt layer, is depicted as an enlarged view. window $(0.3 \mathrm{~mm} \times 3 \mathrm{~mm})$. A potentiostat (ECstat-101, ECfrontier Co., Ltd., Japan) with modified firmware to enable external command control was used to control the bias potentials of the electrochemical cell. An Interface 1000T potentiostat (Gamry Instruments, USA) was also used to confirm the results of $\mathrm{CV}$ measurements.

\section{TEST EXPERIMENTS OF SPECTRO-ELECTROCHEMICAL CELL}

\section{A. CV measurements}

The main difference between our new spectroelectrochemical cell and standard electrochemical cells is the thin-film working electrode with the backside illumination configuration. Hence, CV measurements were carried out on a standard sample to confirm the functionality of the new electrochemical cell. Figure 2 shows cyclic voltammograms recorded using the constructed cell with the sweep rate of $0.1 \mathrm{~V} \mathrm{~s}^{-1}$ in a $0.2 \mathrm{M} \mathrm{H}_{2} \mathrm{SO}_{4}$ aqueous solution deaerated by $\mathrm{N}_{2}$ bubbling. The electrolyte solution was introduced into the cell by using an external liquid pump, and measurements were carried out when the sample flow was stopped. Although the Pt electrode on the window substrate was only $15 \mathrm{~nm}$ thick, the obtained voltammogram is similar to those of the standard electrochemical cells, showing symmetric currents of hydrogen adsorption/desorption (from -0.2 to $+0.05 \mathrm{~V}$ ) and platinum oxide formation (from +0.6 to $1.2 \mathrm{~V}$ )/reduction (from +0.7 to $0.3 \mathrm{~V}$ ). Therefore, we confirmed that the developed cell functioned properly.

A note should be added about the stability of metal film on the windows. In the initial development stage, we used a silicon nitride $(\mathrm{SiN})$ membrane with metal coating on the liquid side as a separator between vacuum and the liquid samples under soft X-ray irradiation. ${ }^{10}$ However, we found that the metal film on the SiN membrane was not stable for repeated $\mathrm{CV}$ measurements, in agreement with reports that the metal films on SiN are not stable enough upon the application of a voltage. ${ }^{8}$ Hence, we tested the conductive silicon

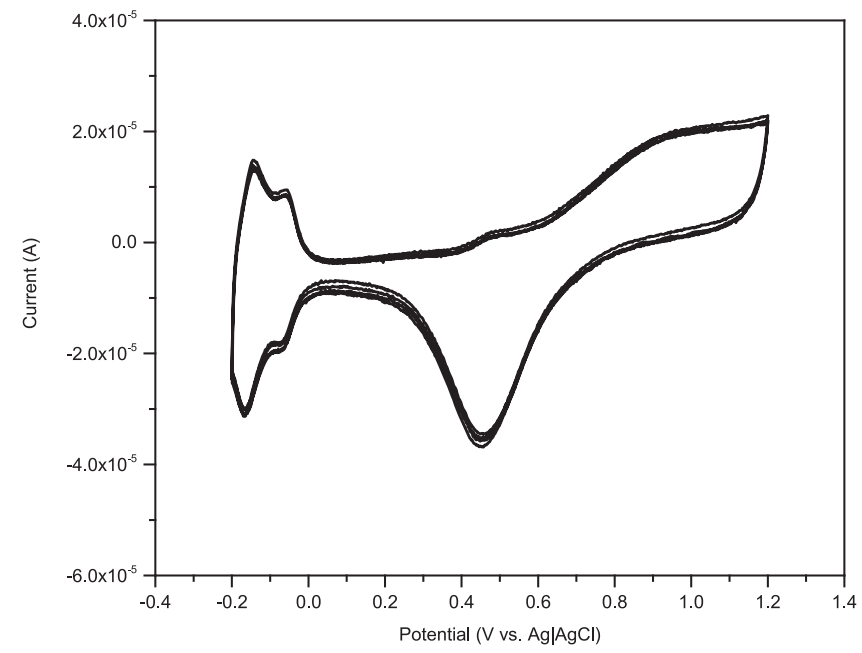

FIG. 2. Cyclic voltammograms of a Pt electrode substrate of the developed electrochemical cell at $0.1 \mathrm{~V} \mathrm{~s}^{-1}$ in $0.2 \mathrm{M}$ deaerated sulfuric acid aqueous solution. 
carbide ( $\mathrm{SiC}$ ) window material instead, on which a Pt film was quite stable under voltage application. In this case, the cyclic voltammogram was recorded after cleaning the electrode by repeated $\mathrm{CV}$ measurements (typically between $-0.4 \mathrm{~V}$ and $1.2 \mathrm{~V}$ for at least 30 cycles).

\section{B. Soft X-ray experiments}

To confirm the functionality of the cell for spectroscopy in the soft X-ray region, O 1s X-ray absorption and emission experiments were performed at the SPring-8 synchrotron radiation facility using the soft X-ray beamline BL17SU. ${ }^{11,12}$ XAS spectra were recorded as the total fluorescence yields (FYs) using a standard 100- $\mathrm{mm}^{2} \mathrm{Si}$ photodiode (IRD AXUV-100G, Opto Diode Corp., USA) facing the window. The photoelectrons emitted from the window by irradiation of soft X-rays were eliminated by placing an electrically biased mesh screen in front of the photodiode. Circularly polarized X-rays were used for both XES and XAS measurements to gain a higher photon flux, and to avoid polarization effects of $\mathrm{XES}^{13,14}$ which are unfavorable in this experiment.

Figures 3 and 4 show the FY-XAS and XES spectra of an aqueous solution of $\mathrm{Pb}$ (II) acetate (Wako Pure Chemical Industry, Japan) in ultrapure water at $0.46 \mathrm{M}$. The sample solution was deaerated by $\mathrm{N}_{2}$ bubbling. The FY-XAS spectrum for the $\mathrm{Pb}$ (II) acetate aqueous solution shows a clear peak structure at around $533 \mathrm{eV}$, which is absent in the spectrum for water. According to a previous observation using X-ray spectroscopy for aqueous acetic acid, acetic acid in aqueous solution shows an evident peak assigned to the $\Pi^{*}$ orbital of the carboxyl group at around $533 \mathrm{eV} .^{6}$ This peak structure is also reported for aqueous solutions of metal acetates such as $\mathrm{K}, \mathrm{Na}, \mathrm{Li}$, and $\mathrm{Zn}$ acetates. ${ }^{15,16}$ Since the equilibrium constant for complex formation between $\mathrm{Pb}$ (II) ions and acetate ions is high, ${ }^{17,18}$ the free and $\mathrm{Pb}$ (II)-coordinated acetate anions are the most probable assignments of this peak. The XES spectrum with excitation energy of $533 \mathrm{eV}$ in Fig. 4 provides further insights into the complex formation. Since the acetate anion in solution is selectively excited at $533 \mathrm{eV}$, the obtained spectrum reflects the electronic state of acetate. Interestingly, the spectrum of

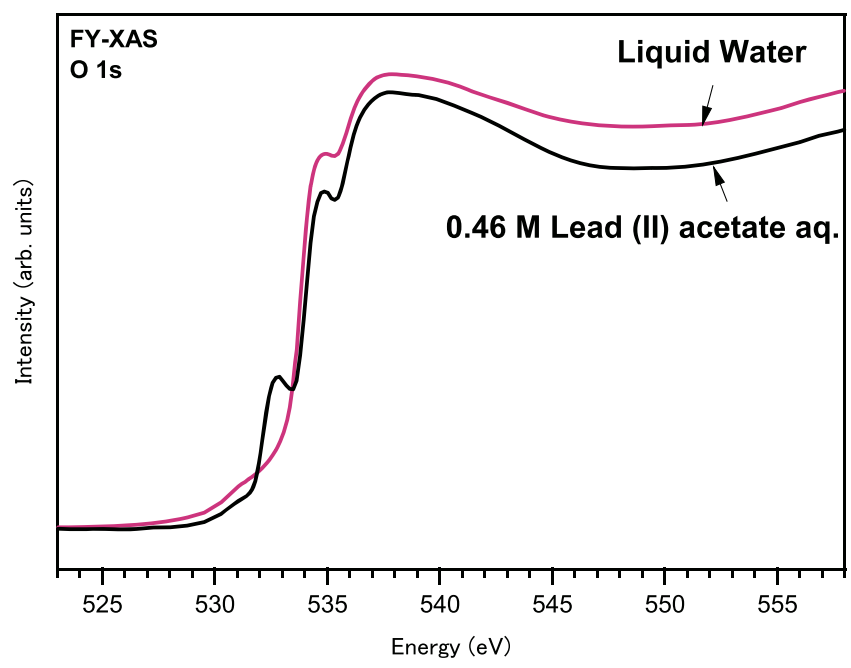

FIG. 3. O 1s FY-XAS of pure water and $0.46 \mathrm{M} \mathrm{Pb}$ (II) acetate solution.

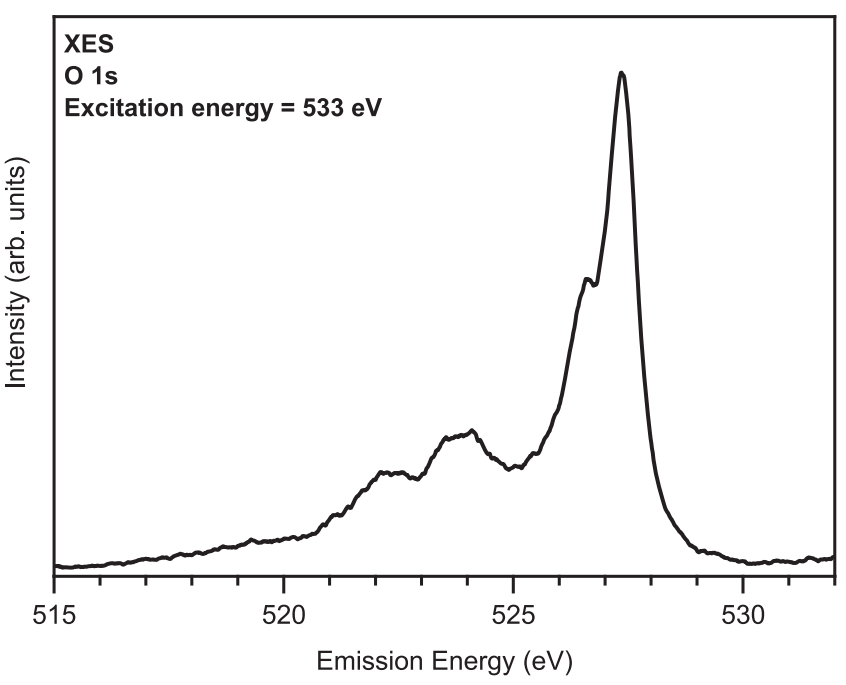

FIG. 4. O 1s XES of $0.46 \mathrm{M} \mathrm{Pb}$ (II) acetate solution with excitation energy of $533 \mathrm{eV}$.

aqueous acetate in $\mathrm{Pb}$ (II) acetate is evidently different from those of the non-coordinated acetate ion in aqueous solution ${ }^{6}$ and previously reported metal acetates. ${ }^{15,16}$ The difference can be attributed to the interaction between a $\mathrm{Pb}$ (II) cation and an acetate anion. However, further investigation is required.

\section{SOFT X-RAY OBSERVATION OF Pb ELECTRODEPOSITION PROCESS}

To demonstrate successful measurements with the developed spectro-electrochemical cell, electrodeposition of $\mathrm{Pb}$ from aqueous $0.46 \mathrm{M} \mathrm{Pb}$ (II) acetate solution on the Pt coated$\mathrm{SiC}$ membrane window was observed by soft X-ray transmission at the $\mathrm{O} 1 \mathrm{~s}$ edge, since $\mathrm{Pb}$ deposition/dissolution in this solution can be easily controlled electrochemically. In this study, we were able to dissolve a metal $\mathrm{Pb}$ film deposited on the surface of a Pt window by applying a potential of $+200 \mathrm{mV}$.

Figure 5 shows the FY-XAS spectra obtained during electroplating. The plating solution, i.e., aqueous $\mathrm{Pb}$ (II) acetate,

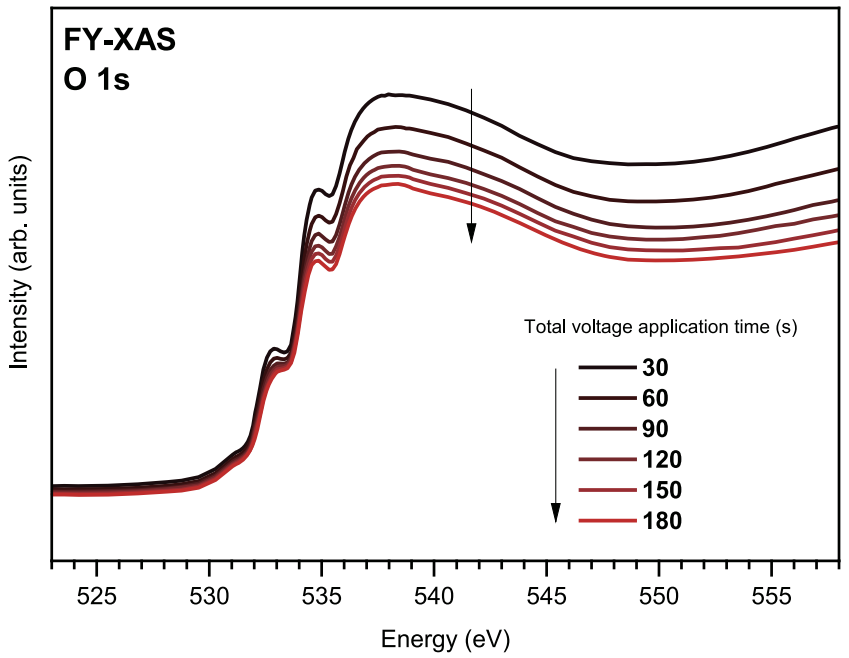

FIG. 5. Time evolution of FY-XAS spectra of $0.46 \mathrm{M} \mathrm{Pb}$ (II) acetate solution at $-600 \mathrm{mV}$ (vs. $\mathrm{Ag} \mid \mathrm{AgCl}$ ). The potential was applied for $30 \mathrm{~s}$ between two FY-XAS measurements. 


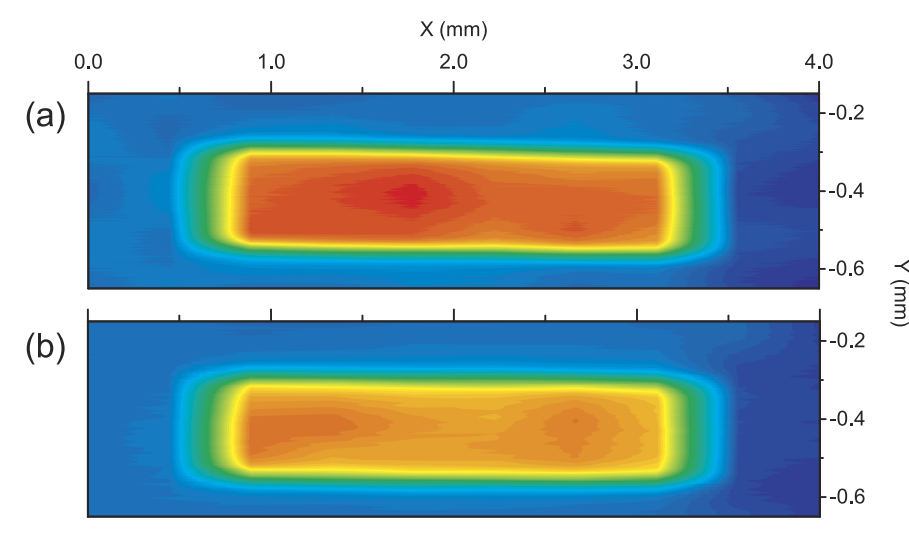

was flowed into the cell using a liquid pump. Measurements were carried out when the sample solution flow was stopped, as the flow pulsation makes the potential unstable. A potential of $-600 \mathrm{mV}$ was applied, which is enough for plating according to our test experiments. To investigate spectral variations of XAS with respect to the total time of potential application, the potential was applied intermittently in $30 \mathrm{~s}$ periods, and each XAS measurement was carried out while the potential was off (open circuit). The overall intensity of the obtained spectra was reduced with the elapsed time because of the $\mathrm{Pb}$ electrodeposition. Transmittance of the window in the $\mathrm{O} 1 \mathrm{~s}$ XAS decreased with increasing thickness of the deposited $\mathrm{Pb}$. Therefore, the gradual $\mathrm{Pb}$ deposition lowered the intensity of the incident beam into the solution, and the overall intensity of O 1s FY-XAS spectra decreased.

Since we have observed the O 1s spectra of FY-XAS, it is impossible to determine the state of $\mathrm{Pb}$ in the electroplated film solely from obtained spectra. Nevertheless, the existence of lead oxides can be ruled out. According to a previous report, the $\mathrm{PbO}$ and $\mathrm{PbO}_{2}$ peaks appear at 530.4 and $530.7 \mathrm{eV}$ in the O 1s XAS spectrum, respectively. ${ }^{19}$ However, the XAS spectra obtained in this study showed no corresponding peak in this region. Hence, we could confirm that a pure $\mathrm{Pb}$ metal without oxides was deposited on the window surface during the experiment.

To confirm the homogeneity of plating, which is also an important factor for the electrochemical cell performance, the intensity mapping of soft X-ray fluorescence from the $\mathrm{Pb}$ acetate solution was performed for the whole window area. Figure 6 shows the results before and after plating. Plating was performed with an applied potential of $-450 \mathrm{mV}$ and a total application time of $180 \mathrm{~s}$. The excitation energy was tuned to $550 \mathrm{eV}$ for observing the oxygen signals. There is no evident change in the rectangular region (corresponding to the window area) after the plating, except for an almost uniform intensity reduction. Hence, the mapping results validated the design of the spectro-electrochemical cell.

To further investigate the time evolution of the electrochemical deposition, the fluorescence intensity at the specific excitation energy of $550 \mathrm{eV}$ was measured in real time. Figure 7 shows the time evolution of fluorescence intensity. The potential was applied cyclically for $30 \mathrm{~s}$ duration with $60 \mathrm{~s}$ intervals.
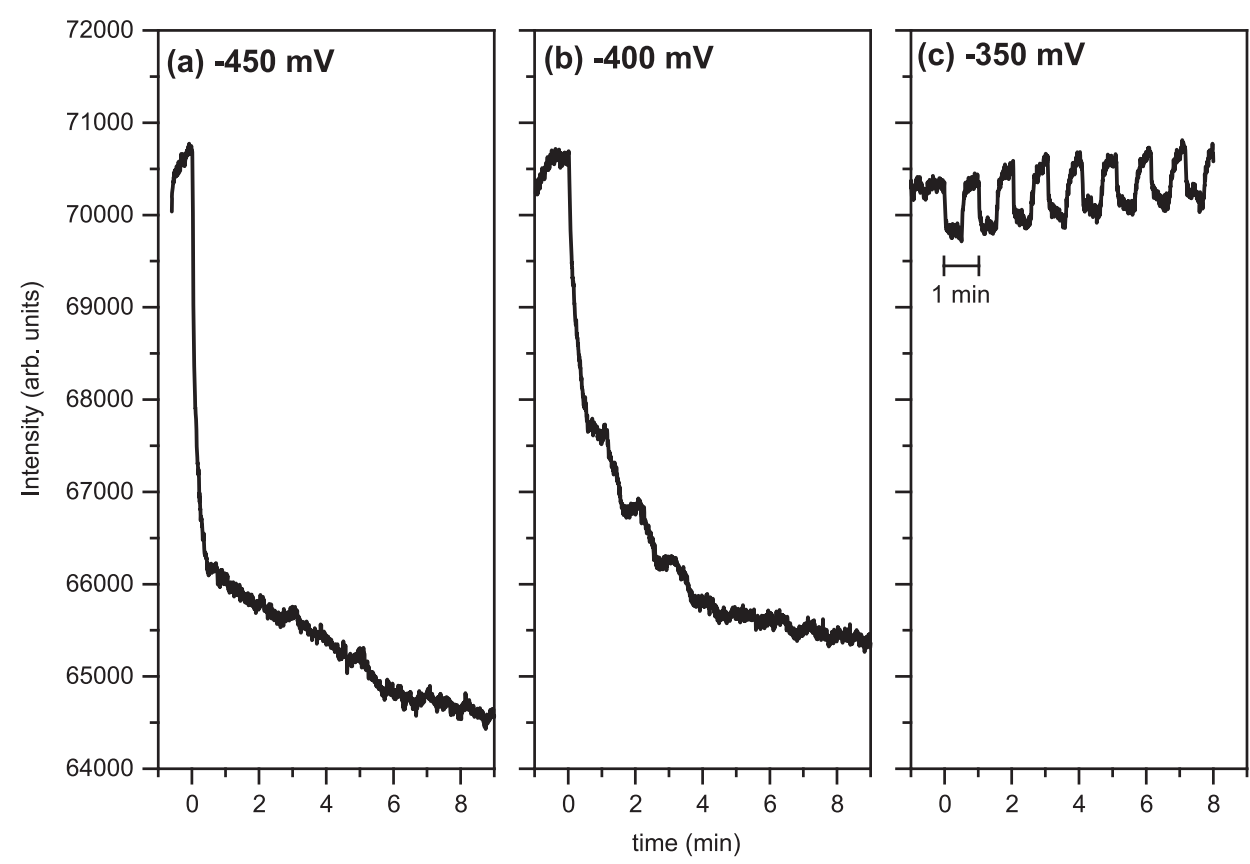

FIG. 7. Time evolution of fluorescence intensity of $0.46 \mathrm{M} \mathrm{Pb}$ (II) acetate solution with an excitation energy of $550 \mathrm{eV}$, at the applied potentials of (a) -450 , (b) -400 , and (c) $-350 \mathrm{mV}$ vs. $\mathrm{Ag} \mid \mathrm{AgCl}$. Time 0 denotes the starting time of the first voltage application.

FIG. 6. O 1s fluorescence intensity mapping (a) before
and (b) after electroplating. The excitation energy was tuned to $550 \mathrm{eV}$. 
At the potentials of -450 and $-400 \mathrm{mV}$ [Figs. 7(a) and 7(b)], a gradual decrease of FY with periodic steps was observed, with a step length of about $60 \mathrm{~s}$ that corresponds well to the time period of the potential application. The stepwise intensity decrease indicates that the thin film window was plated with $\mathrm{Pb}$ at those potential settings under well-controlled conditions, with the FY intensity decreasing more rapidly under a more negative applied potential.

The rate of the FY intensity decrease (i.e., the deposition speed) slows down as the total voltage application time increases. This slowed down deposition speed might be connected to the reduced $\mathrm{Pb}$ concentration around the surface of the $\mathrm{Pb}$-deposited window. Diffusion in the sample liquid is the only way to supply $\mathrm{Pb}$ to around the window, and this supply is not enough for growing a $\mathrm{Pb}$ film continuously in this case.

At $-350 \mathrm{mV}$, the fluorescence intensity remained almost the same after repeated cycles of potential application [Fig. 7(c)], which was very different from those changes observed at -450 and $-400 \mathrm{mV}$ [Figs. 7(a) and 7(b)]. In other words, the $\mathrm{Pb}$ deposition layer on the window did not become thicker after the potential application. We therefore conclude that no $\mathrm{Pb}$ deposition occurred on the surface at $-350 \mathrm{mV}$. However, the response in fluorescence intensity with the rectangular wave shape was observed at $-350 \mathrm{mV}$. This means that the transmission is decreased only while the potential was applied. The response to voltage application accounts for about $1 \%$ of the fluorescence intensity. According to recent electronic state observation using X-ray photoelectron spectroscopy, the electronic state at the electrode interface up to $10 \mathrm{~nm}$ in depth was affected by the voltage. ${ }^{20}$ By taking the probing depth of soft X-ray into account (around $400 \mathrm{~nm}$ for soft X-rays above the energy of the $\mathrm{O} 1$ s edge, with $45^{\circ}$ incident angle), the $1 \%$ variation of FY intensity is reasonable, considering that the observed transmission reduction for soft $\mathrm{X}$-rays at the oxygen edge is a phenomenon on the electrode surface. $\mathrm{Pb}$ ions and positively charged $\mathrm{Pb}$-acetate complexes should accumulate on the electrode surface due to the application of a negative potential. At $-350 \mathrm{mV}$, the applied potential was not enough to form a metal film on the electrode, and no $\mathrm{Pb}$ deposition occurred on the surface. As a result, the accumulated ions were released from the electrode window surface, and the transmission was restored by switching off the potential control. Hence, the FY response with the rectangular wave shape can be considered as the density variation of $\mathrm{Pb}$ based cation species near the electrode surface due to voltage application.

\section{v. CONCLUSION}

We developed a spectro-electrochemical cell for use in the soft X-ray region. The cell design was based on a previously developed liquid flow-through cell for samples under atmospheric pressure. To realize soft X-ray observation of surface electrochemical reactions, a film with a deposited $\mathrm{Pt}$ layer was used. In the constructed cell with three-electrode configuration, a Pt deposition layer on the surface of the silicon carbide membrane was used as the working electrode. The design and electrochemical performance of the cell were evaluated by cyclic voltammetry, a standard electrochemical measurement, of $\mathrm{H}_{2} \mathrm{SO}_{4}$ aqueous solution. Its functionality as a spectroscopy cell in the soft $\mathrm{X}$-ray region was confirmed by $\mathrm{O} 1 \mathrm{~s}$ X-ray absorption and emission measurements for aqueous $\mathrm{Pb}$ (II) acetate. To demonstrate the overall performance of the cell, electroplating of $\mathrm{Pb}$ on the membrane window in aqueous $\mathrm{Pb}$ (II) acetate was investigated. We successfully observed a decrease of transmission in the $\mathrm{O} 1 \mathrm{~s}$ region by XAS measurements, as well as real-time monitoring of the total yield of X-ray emission during electroplating of metal $\mathrm{Pb}$.

\section{ACKNOWLEDGMENTS}

This work was partly supported by the research project "Development of Advanced PEFC Utilization Technologies, Development of Fundamental Technologies for PEFC Promotion, Highly-Coupled Analysis of Phenomena in MEA and its Constituents and Evaluation of Cell Performance" of NEDO (New Energy and Industrial Technology Development Organization), Japan. This work was also partly supported by JSPS (Japan Society for the Promotion of Science) KAKENHI Grant No. 26870857. Experiments were carried out at SPring8 BL17SU with the approval of the RIKEN SPring-8 Center (Proposal Nos. 20160069 and 20170077). We would like to thank Dr. Masaki Oura (RIKEN SPring-8 Center) for his valuable help with experiments at BL17SU. The authors acknowledge Dr. Hidemi Arai, Dr. Eiichi Kobayashi (Kyushu Synchrotron Light Research Center), and Dr. Yoshihisa Harada (The Institute for Solid State Physics, The University of Tokyo) for contributions in the early stage of developing this spectroelectrochemical cell and Ms. Yuu Sasaki for support in soft $\mathrm{X}$-ray experiments.

${ }^{1}$ Yu, S.-S. Chang, C.-L. Lee, and C. R. C. Wang, J. Phys. Chem. B 101, 6661 (1997).

${ }^{2}$ R. Xiao, S. I. Cho, R. Liu, and S. B. Lee, J. Am. Chem. Soc. 129, 4483 (2007).

${ }^{3}$ L. Chen, Y. Tang, K. Wang, C. Liu, and S. Luo, Electrochem. Commun. 13, 133 (2011).

${ }^{4}$ J. H. Guo, Y. Luo, A. Augustsson, J. E. Rubensson, C. Såthe, H. Ågren, H. Siegbahn, and J. Nordgren, Phys. Rev. Lett. 89, 137402 (2002).

${ }^{5}$ T. Tokushima, Y. Harada, O. Takahashi, Y. Senba, H. Ohashi, L. G. M. Pettersson, A. Nilsson, and S. Shin, Chem. Phys. Lett. 460, 387 (2008).

${ }^{6}$ Y. Horikawa, T. Tokushima, Y. Harada, O. Takahashi, A. Chainani, Y. Senba, H. Ohashi, A. Hiraya, and S. Shin, Phys. Chem. Chem. Phys. 11, 8676 (2009).

${ }^{7}$ P. Jiang, J.-L. Chen, F. Borondics, P.-A. Glans, M. W. West, C.-L. Chang, M. Salmeron, and J. H. Guo, Electrochem. Commun. 12, 820 (2010).

${ }^{8}$ D. K. Bora, P.-A. Glans, J. Pepper, Y.-S. Liu, C. Du, D. W. Wang, and J.-H. Guo, Rev. Sci. Instrum. 85, 043106 (2014).

${ }^{9}$ M. Nagasaka, H. Yuzawa, T. Horigome, and N. Kosugi, Rev. Sci. Instrum. 85, 104105 (2014).

${ }^{10}$ T. Tokushima, Y. Harada, Y. Horikawa, O. Takahashi, Y. Senba, H. Ohashi, L. G. M. Pettersson, A. Nilsson, and S. Shin, J. Electron Spectrosc. Relat. Phenom. 177, 192 (2010).

${ }^{11}$ H. Ohashi, Y. Senba, H. Kishimoto, T. Miura, E. Ishiguro, T. Takeuchi, M. Oura, K. Shirasawa, T. Tanaka, and M. Takeuchi, AIP Conf. Proc. 879, 523 (2007).

${ }^{12}$ Y. Senba, H. Ohashi, H. Kishimoto, T. Miura, S. Goto, S. Shin, T. Shintake, T. Ishikawa, J.-Y. Choi, and S. Rah, AIP Conf. Proc. 879, 718 (2007).

${ }^{13}$ Y. Horikawa, T. Tokushima, A. Hiraya, and S. Shin, Phys. Chem. Chem. Phys. 12, 9165 (2010).

${ }^{14}$ T. Tokushima, Y. Horikawa, H. Arai, Y. Harada, O. Takahashi, L. G. M. Pettersson, A. Nilsson, and S. Shin, J. Chem. Phys. 136, 044517 (2012). 
${ }^{15}$ E. F. Aziz, N. Ottosson, S. Eisebitt, W. Eberhardt, B. Jagoda-Cwiklik, R. Vácha, P. Jungwirth, and B. Winter, J. Phys. Chem. B 112, 12567 (2008). ${ }^{16}$ R. Golnak, K. Atak, E. Suljoti, K. F. Hodeck, K. M. Lange, M. A. Soldatov, N. Engel, and E. F. Aziz, Phys. Chem. Chem. Phys. 15, 8046 (2013).

${ }^{17}$ M. Yasuda, K. Yamasaki, and H. Ohtaki, Bull. Chem. Soc. Jpn. 33, 1067 (1960).
${ }^{18}$ J. W. Bunting and K. M. Thong, Can. J. Chem. 48, 1654 (1970).

${ }^{19}$ D. J. Payne, R. G. Egdell, D. S. L. Law, P. A. Glans, T. Learmonth, K. E. Smith, J. H. Guo, A. Walsh, and G. W. Watson, J. Mater. Chem. 17, 267 (2007).

${ }^{20}$ M. Favaro, B. Jeong, P. N. Ross, J. Yano, Z. Hussain, Z. Liu, and E. J. Crumlin, Nat. Commun. 7, 12695 (2016). 